\title{
Microalgae Nannochloropsis oceanica as a future new natural source of vitamin D3
}

\author{
Ljubic, Anita; Jacobsen, Charlotte; Holdt, Susan Løvstad; Jakobsen, Jette
}

Published in:

Food Chemistry

Link to article, DOI:

10.1016/j.foodchem.2020.126627

Publication date:

2020

Document Version

Peer reviewed version

Link back to DTU Orbit

Citation (APA):

Ljubic, A., Jacobsen, C., Holdt, S. L., \& Jakobsen, J. (2020). Microalgae Nannochloropsis oceanica as a future new natural source of vitamin $\mathrm{D}_{3}$. Food Chemistry, 320, [126627].

https://doi.org/10.1016/j.foodchem.2020.126627

\section{General rights}

Copyright and moral rights for the publications made accessible in the public portal are retained by the authors and/or other copyright owners and it is a condition of accessing publications that users recognise and abide by the legal requirements associated with these rights.

- Users may download and print one copy of any publication from the public portal for the purpose of private study or research.

- You may not further distribute the material or use it for any profit-making activity or commercial gain

- You may freely distribute the URL identifying the publication in the public portal 
1 Microalgae Nannochloropsis oceanica as a future new natural source of

2 vitamin $\mathrm{D}_{3}$

3

4 Anita Ljubic*, Charlotte Jacobsen, Susan L. Holdt and Jette Jakobsen

5

6

Technical University of Denmark, National Food Institute, Kemitorvet, Kongens Lyngby 2800, Denmark.

7 *aniljub@food.dtu.dk

8

9

10

11

12

13

14

15

16

17

18

19

20

21

22

23

24

25

26

27

28

29

30

31

32

33 5 6 0 1 32 33

\section{Abstract}

For the last two decades there has been a rise in awareness about the general low dietary intake of vitamin $D_{3}$. Fish have the highest natural content of vitamin $D_{3}$, which is suggested to originate from zooplankton and microalgae. However there are no studies reporting which microalgal species may be the source of vitamin $\mathrm{D}_{3}$. In this study, four selected microalgal species were cultivated during exposure of artificial UVB. The effect of UVB dose on the growth and biochemical composition of the cells (vitamin $\mathrm{D}_{3}$, PUFAs and carotenoids) was evaluated. Of the four species, exclusively Nannochloropsis oceanica was able to produce vitamin $\mathrm{D}_{3}$ (up to $1 \pm 0.3$ $\mu \mathrm{g} / \mathrm{g} \mathrm{DM})$, and production was significantly enhanced by increasing the dose of the UVB. These findings suggest that $N$. oceanica exposed to artificial UVB could be used as a new natural source of vitamin $\mathrm{D}_{3}$, either as direct source or through animal feed.

\section{Keywords}

7-dehydrocholesterol, carotenoids, fatty acids, microalgal cultivation, ultraviolet radiation 7 8 9 


\section{Introduction}

Vitamin D belongs to a group of lipid soluble sterols with the two major forms - vitamin $\mathrm{D}_{3}$ (cholecalciferol) and vitamin $\mathrm{D}_{2}$ (ergocalciferol). Vitamin $\mathrm{D}_{3}$ and its metabolites are found mainly in foodstuffs of animal origin, such as fish, eggs and meat, whereas vitamin $\mathrm{D}_{2}$ can be found in wild mushrooms, and ultraviolet-B (UVB) exposed fungi and yeast (Jäpelt \& Jakobsen, 2013). When consumed, vitamin $\mathrm{D}_{3}$ is initially converted to 25 -hydroxyvitamin $\mathrm{D}$ in the liver, and further in the kidney hydroxylated to the metabolically active form 1,25-dihydroxyvitamin D (Pilz et al., 2018). Besides the dietary intake, vitamin $\mathrm{D}_{3}$ can be synthesized in skin cells during exposure to sun light. UVB light enables the conversion of naturally present 7dehydrocholesterol (provitamin $\mathrm{D}_{3}$ ) to vitamin $\mathrm{D}_{3}$ (Pilz et al., 2018).

Vitamin D deficiency and insufficiency is a world-wide problem, which affect more than one billion people, and on a yearly basis e.g. around $13 \%$ of the European population is vitamin $\mathrm{D}_{3}$ deficient (vitamin $\mathrm{D}_{3}$ status $<30 \mathrm{nmol} / \mathrm{L}$ ) and $40 \%$ vitamin $\mathrm{D}_{3}$ insufficient (vitamin $\mathrm{D}_{3}$ status < $50 \mathrm{nmol} / \mathrm{L}$ ) (Cashman et. al, 2016a; Holick, 2017). The recommended daily intake is 10-20 $\mu \mathrm{g}$ vitamin $D_{3}$ per day in Europe and US (IOM, 2011; NNR, 2014; EFSA, 2016). The estimated intake of vitamin $\mathrm{D}_{3}$ is only around 3-7 $\mu \mathrm{g}$ /day, which is far below daily recommendations (Cashman \& Kiely, 2016b). An alternative to dietary intake of vitamin D is the production of vitamin D in human skin by UVB-exposure (Pilz et al., 2018). This production is limited in places above $35^{\circ}$ latitude where the amount of UVB reaching the earth's surface depend on season (Webb, 2006). O`Neill et al. (2016) assessed vitamin D-effective UVB availability for several European countries using a validated UV irradiance model, which made use of the average UVBmeasurements over a 10-year period. As an example in Copenhagen, Denmark $\left(55^{\circ} \mathrm{N}\right)$ the maximum UVB dose was shown to be in June and July at $5 \mathrm{~kJ} / \mathrm{m}^{2} / \mathrm{month}$, while from October to March no production of vitamin D is present (vitamin D winter months). In contrast in Southern Europe, represented by Athens, Greece $\left(37^{\circ} \mathrm{N}\right)$ the maximum was $9-10 \mathrm{~kJ} / \mathrm{m}^{2} / \mathrm{month}$ in June and July, and only two vitamin D winter months (December and January), and as expected at Crete, Greece $\left(35^{\circ} \mathrm{N}\right)$, UVB-exposure is efficient for vitamin D production in human all year round. Apart from geographic latitude, vitamin $\mathrm{D}_{3}$ synthesis in skin can be reduced for many other reasons like low outdoor activity due to unhealthy lifestyle, immobility of elderly people, or severe air pollution. Therefore, intake of vitamin $\mathrm{D}_{3}$ through nutrition plays an essential role to maintain healthy vitamin $\mathrm{D}_{3}$ levels.

Fish and fish products are major dietary sources of vitamin $\mathrm{D}_{3}$, especially salmon (Salmo salar) and rainbow trout (Oncorhynchus mykiss) (Jakobsen \& Smith, 2017). However, the origin of 
vitamin $\mathrm{D}$ in fish still remains unclear. The photochemical production of vitamin $\mathrm{D}_{3}$ in fish is doubtful, due to the insufficient UV radiation in their natural habitats. Therefore, it is suggested that vitamin $\mathrm{D}_{3}$ present in fish originates from zooplankton and microalgae (Takeuchi, Okano, Tanda \& Kobayashi, 1991; Sunita Rao \& Raghuramulu, 1996). Microalgae have been recognized as a potential source for various high-value ingredients with positive health effects, such as polyunsaturated fatty acids (PUFAs), pigments, vitamins, peptides and many other bioactive compounds. Microalgae can be found at the surface of the water bodies so it can be assumed that vitamin $D_{3}$ is synthesized due to the sun exposure. Microalgae should be able to synthesize 7dehydrocholesterol in order to synthesize vitamin $\mathrm{D}_{3}$ by UVB exposure, if they use the same metabolic pathway as vertebrates. Sterols in microalgae display enormous diversity, due to the large number of classes and their composition varies depending on growth stage, light spectrum and temperature (Véron, Billard, Dauguet, \& Hartmann 1996), which means it is hard to make any general conclusions about the ability of microalgae to synthesize vitamin D.

To our knowledge there are no studies reporting which microalgal species may be the source of vitamin $\mathrm{D}_{3}$. In this study, four selected microalgal species from different classes, Chlorella minutissima from Chlorophyta, Nannochloropsis oceanica from Eustigmatophyta, Arthrospira maxima from Cyanophyta and Rhodomonas salina from Rhodophyta were cultivated and exposed to artificial UVB. Furthermore, the dependence on dose was investigated by varying the exposure time and distance from the light source. In addition to vitamin $\mathrm{D}_{3}$ concentrations, also the effect of UVB light on the microalgal growth and changes in the biochemical composition of the cells were determined, due to the high nutritional importance of the omega-3-fatty acids and pigments in microalgal biomass.

\section{Materials and methods}

\subsection{Microalgal production}

Four microalgal species were purchased: Chlorella minutissima (UTEX 2219, Utex Culture Collection of Algae, University of Texas, Austin, USA) Nannochloropsis oceanica (NIVA 2/03, Norwegian Institute for water research, Oslo, Norway) Arthrospira maxima (SAG 84.79, Culture Collection of Algae, Göttingen, Germany) and Rhodomonas salina (DTU Aqua, Technical University of Denmark, Lyngby, Denmark). The inoculum was prepared in Guillard F/2 medium (Guillard, 1962) for salt water species N.oceanica and R. salina; Zarrouk medium (Zarrouk, 
1966) was used for A. platensis and Walne's medium (Walne, 1970) for cultivating C. minutissima.

The cultivation experiments were carried out in triplicates using $1 \mathrm{~L}$ and $5 \mathrm{~L}$ GS Schott bottles for up-scaling. The cultures were aerated with a mixture of carbon dioxide (5\%) and sterile air. Cultivation temperature was $23 \pm 1{ }^{\circ} \mathrm{C}$ and $\mathrm{pH} 7.5 \pm 0.5$, except for A. platensis where $\mathrm{pH}$ was 9.5 \pm 0.5 . $\mathrm{pH}$ monitoring was performed by Milwaukee MC-122-pH controller (Milwaukee Electronics, Szeged, Hungary) equipped with a solenoid valve to control $\mathrm{CO}_{2}$ addition. The LED light (SunFlux A/S, Glostrup, Denmark) provided before UVB treatment had an intensity of 110$120 \mu \mathrm{mol}$ photon $/ \mathrm{m}^{2} / \mathrm{s}$ (measured on the outer side of the bottle; Universal Light Meter ULM500, Heinz Walz GmbH, Effeltrich, Germany).

Cultures (in their exponential growth phase) were transferred from 5 L GS Schott bottles into transparent, rectangle-shaped, plastic containers $(25 \mathrm{~cm}$ x $15 \mathrm{~cm}$ x $20 \mathrm{~cm})$ in order to increase the surface of the culture for the UVB exposure.

\subsection{UVB-treatment}

For the UVB experiments UVB tube $\left(\mathrm{D}_{3}{ }^{+} \mathrm{UV}\right.$ Flood DESERT, $24 \mathrm{~W}$ tubes, Arcadia, United Kingdom) with its main wavelength at $312 \mathrm{~nm}$ was used. For quantification of UVB irradiance dose over the microalgal cultures a handheld ILT 1400-BL photometer equipped with a SEL005/TLS312/TD detector (International Light Technologies, Peabody, MA, USA) was used within the three distances from the surface of the microalgal culture; $5 \mathrm{~cm}, 10 \mathrm{~cm}$ and $15 \mathrm{~cm}$.

\subsubsection{Experiment 1}

In order to investigate ability of microalgae to synthesize vitamin $D_{3}$, as a preliminary experiment, all four microalgae species were exposed to UVB for 3, 6, 18 and 24 hours per day for 7 days, which corresponds $3 \mathrm{~kJ} / \mathrm{m}^{2} /$ day, $6 \mathrm{~kJ} / \mathrm{m}^{2} /$ day, $16 \mathrm{~kJ} / \mathrm{m}^{2} /$ day and $22 \mathrm{~kJ} / \mathrm{m}^{2} /$ day, respectively. The UVB-tube was placed at distance of $10 \mathrm{~cm}$ from the surface of the cultured microalgae. Growth was monitored every 24 hours by taking $5 \mathrm{~mL}$ of culture and measuring optical density at $750 \mathrm{~nm}$. A control culture received no UVB exposure.

\subsubsection{Experiment 2}

Species ( $N$. oceanica) that produced vitamin $\mathrm{D}_{3}$ following UVB exposure was tested further for the effect of dose, which was varied by exposure time and distance to the surface of the microalgal culture.

a. UVB exposure for 1, 3 and 6 days ( $24 \mathrm{~h}$ a day) at a distance of $15 \mathrm{~cm}$ above the surface of the culture, provided a dose of $15 \mathrm{~kJ} / \mathrm{m}^{2} /$ day. 
b. UVB exposure for 5 days ( $24 \mathrm{~h}$ a day) at distance of $5 \mathrm{~cm}, 10 \mathrm{~cm}$ and $15 \mathrm{~cm}$ from the surface of the microalgal culture, provided a dose of $36 \mathrm{~kJ} / \mathrm{m}^{2} /$ day, $22 \mathrm{~kJ} / \mathrm{m}^{2} /$ day and $15 \mathrm{~kJ} / \mathrm{m}^{2} / \mathrm{day}$, respectively. A control culture received no UVB exposure.

\subsection{Sampling}

For chemical analysis $500 \mathrm{~mL}$ of culture was sampled. In order to achieve biomass separation, samples were centrifuged (refrigerated centrifuge, IEC Centra-GP8R, Buckinghamshire, England) at $8000 \mathrm{~g}$ for A. maxima, $6000 \mathrm{~g}$ for $N$. oceanica and C. minutissima and $4000 \mathrm{~g}$ for $R$. salina. Biomass was washed, freeze-dried (Beta 1-8, Martin Christ GmbH, Osterode, Germany) and stored at $-20{ }^{\circ} \mathrm{C}$ until analysis.

\subsection{Biochemical analysis}

\section{Total lipid content}

Lipid extraction was preformed according to Bligh \& Dyer method (1959), with a reduced amount of solvent (30 mL of each). Approximately $1 \mathrm{~g}$ of the freeze-dried microalgal biomass was weighted into extraction glass. Extraction was carried out by subsequent addition of methanol, chloroform and water while stirring. In order to separate phases - methanol/water from chloroform/oil, samples were centrifuged at $1400 \mathrm{~g}$ for $10 \mathrm{~min}$. Bligh \& Dyer extracts were used for analyses of the total lipid content, fatty acid composition and tocopherols. Determination of total lipid content was done by weighing approximately $15 \mathrm{~g}$ of extract in beakers and keeping it overnight in a fume hood in order to evaporate chloroform.

\section{Fatty acids}

Fatty acid profile was determined based on the American Oil Chemist's Society (AOCS) official method Ce 1i-07 (Firestone, 2009) with slight modifications. Approximately $3 \mathrm{~g}$ of Bligh \& Dyer extract was weighted in methylation glass tube and dried under the stream of nitrogen. A mixture of $100 \mu \mathrm{L}$ of internal standard solution (C23:0), $100 \mu \mathrm{L}$ of toluene and $200 \mu \mathrm{L}$ of heptane with butylated hydroxytoluene (BHT) was added to extract. Methylation was performed in a microwave oven (Microwave 3000 SOLV, Anton Paar, Ashland, VA, USA) for 10 min at 100 ${ }^{\circ} \mathrm{C}$ and power of 500 watts. After methylation, $0.7 \mathrm{~mL}$ of heptane and $1 \mathrm{~mL}$ of saturated salt water $\left(0.36 \mathrm{~g} \mathrm{NaCl} / \mathrm{g} \mathrm{H}_{2} \mathrm{O}\right.$, at $\left.20^{\circ} \mathrm{C}\right)$ were added to the glass tube. The upper phase (heptane) was transferred into GC vials and analyzed by gas chromatography (HP-5890 A, Agilent Technologies, Santa Clara, CA, USA). Fatty acid methyl esters were separated by the GC column Agilent DB wax 127-7012 (10 m x $100 \mu \mathrm{m}$ x $0.1 \mu \mathrm{m})$ (Agilent technologies, Santa Clara, CA, 
USA). Standard mix of fatty acids methyl esters (Nu Check Prep 68D, Elysian, MN, USA) was used for fatty acid identification. Fatty acids were reported as area $\%$ of total fatty acids.

Pigments

Pigment analysis was done according to the method described by Safafar, Wagenen, Møller \& Jacobsen (2015). Approximately $0.03 \mathrm{~g}$ of the freeze-dried microalgal biomass was placed in a $10 \mathrm{ml}$ centrifugation tube. Methanol containing the internal standard and antioxidant BHT was added to the sample and they were placed in a sonication bath (Buch \& Holm A/S, Herlev, Denmark) for $15 \mathrm{~min}$ at $5 \pm 2{ }^{\circ} \mathrm{C}$ in order to extract pigments. Extraction was repeated three times and extracts were collected subsequently. Pigment analysis was performed by HPLC using Agilent 1100 Liquid Chromatograph with DAD 400-700 nm. Separation was carried out on a Zorbax Eclipse C8 column 150 mm x 46 mm x $3.5 \mu \mathrm{m}$ (Phenomenex Inc. CA, USA). The mobile phase being a mixture of $70 \%$ methanol $+30 \%$ of $0.028 \mathrm{M}$ tertiary butyl ammonium acetate in water used for gradient elution as described by Safafar et al. (2015) and at a flow rate of 1.1 $\mathrm{mL} / \mathrm{min}$ and a run time of $40 \mathrm{~min}$. DHI pigment standard mix (DHI LAB Products, Horsholm, Denmark) was used for identification of peaks, of which 18 of different carotenoids can be detected and 4 chlorophylls. BHT was detected at $280 \mathrm{~nm}$, while detection of chlorophylls and carotenoids was done at $660 \mathrm{~nm}$ and $440 \mathrm{~nm}$, respectively. Pigments are reported as mg/g dry biomass.

\section{Vitamin D}

Vitamin D analysis was performed as previously described by Barnkob, Petersen, Nielsen \& Jakobsen (2019). Briefly, $0.1 \mathrm{~g}$ of freeze-dried microalgae was weighed, added $8 \mathrm{ng} d 6$-vitamin $\mathrm{D}_{3}$ (Chemaphor, Ottava, Canada) as internal standard and saponified over night at room temperature. The unsaponifiable matter was extracted with $20 \%$ ethyl acetate in $n$-heptane by liquid/liquid extraction, cleaned-up by a SPE-hybrid solid-phase extraction, and derivatized with 4-phenyl-1,2,4-triazole-3,5-dione (PTAD; Sigma-Aldrich, Steinheim, Germany) for 5 min in darkness. Quantification of vitamin $\mathrm{D}_{3}$ and vitamin $\mathrm{D}_{2}$ using a LC-MS/MS consisting of an Agilent 1200 Series HPLC and Agilent 6470 Triple Quadrupole MS (Santa Clara, CA) coupled with a C18 column (Ascentis Expess, $2.1 \mathrm{~mm}$ x $10 \mathrm{~cm}, 2.7 \mu \mathrm{m}$; Supelco Analytical, Bellafonte, PA) and a gradient mobile phase of water:methanol including $2.5 \mathrm{mM}$ ammonium phosphate. Limit of quantification (LOQ) for both vitamers was $4 \mathrm{ng} / \mathrm{g}$ dry biomass. The analyses for vitamin $\mathrm{D}$ were conducted in laboratory environment accredited to perform the analyses according to ISO17025 (2015).

\subsection{Statistical analysis}


197

198

199

200

201

202

203

204

205

206

207

208

209

210

211

212

213

214

215

216

217

218

219

220

221

222

223

224

225

226

227

228

All biological experiments were performed in three replicates. The results are given as the mean \pm standard deviation (SD). One-way analysis of variance (ANOVA) was used to determine significant difference in the vitamin $\mathrm{D}_{3}$ content between the individual groups. Tukey's post hoc test was used to detect significant differences between groups where p-values $<0.05$ were considered significant. Association between vitamin $\mathrm{D}_{3}$ content and UVB dose was assessed with Pearson's correlation coefficient using the Data Analysis function in Excel (version 2010, Microsoft, Redmond, WA, USA). The Statistica v. 13.2 software (USA) was used for all other statistical analyses.

\section{Results}

The vitamin $\mathrm{D}_{3}$ content in the four selected microalgal species for experiment 1 is shown in Table 1. N. oceancia was the only tested species that contained vitamin $\mathrm{D}_{3}$ after UVB exposure. Results suggest that concentration of vitamin $\mathrm{D}_{3}$ increases with the increase of the applied UVB dose. Pearson correlation coefficient was 0.88 indicating a strong positive linear relationship between provided UVB dose and vitamin $\mathrm{D}_{3}$ content (data not shown).

Vitamin $\mathrm{D}_{3}$ content in $N$. oceanica increased significantly $(\mathrm{p}<0.05)$ over 6 days of constant UVB exposure in experiment $2 \mathrm{a}$, providing a dose of $15 \mathrm{~kJ} / \mathrm{m}^{2} /$ day (Figure 1a). By decreasing the distance between the UVB lamp and the microalgal cultures from $15 \mathrm{~cm}$ to $5 \mathrm{~cm}$, which corresponds $15 \mathrm{~kJ} / \mathrm{m}^{2} /$ day and $36 \mathrm{~kJ} / \mathrm{m}^{2} /$ day, respectively, there was a significant increase in $\mathrm{D}_{3}$ concentration (Figure $1 b$ ). Furthermore, besides vitamin $\mathrm{D}_{3}$, lower quantities of vitamin $\mathrm{D}_{2}$ were also found in $N$. oceanica, as well as in microalgae $R$. salina (data not shown). Vitamin $\mathrm{D}_{2}$ content was increasing with the increase of the UVB dose and the highest measured content was $0.27 \pm$ $0.08 \mu \mathrm{g} / \mathrm{g}$ dry matter after the UVB dose of $36 \mathrm{~kJ} / \mathrm{m}^{2} /$ day. Rhodomonas salina contained up to $0.20 \mu \mathrm{g} / \mathrm{g}$ dry matter after exposure to UVB dose of $6 \mathrm{~kJ} / \mathrm{m}^{2} /$ day. All the other tested species showed to have vitamin $\mathrm{D}_{2}$ content below the limit of quantification $(<0.004 \mu \mathrm{g} / \mathrm{g}$ dry matter).

Effect of different doses of UVB on the cell growth and biochemical composition of $N$. oceanica was determined by monitoring growth on a daily basis and analyzing content of high value compounds. The measured content of total lipids, PUFAs, carotenoids and chlorophylls under different UVB exposure is displayed in Table 2. The total lipid content tended to increase by the increase of the UVB exposure, whereas PUFAs, chlorophylls and carotenoids content decreased. Surprisingly, the lipid content was significantly lower in the biomass treated with $3 \mathrm{~kJ} / \mathrm{m}^{2} /$ day and $6 \mathrm{~kJ} / \mathrm{m}^{2} /$ day compared to the untreated biomass. However, biomass that was exposed to the $16 \mathrm{~kJ} / \mathrm{m}^{2} /$ day of UVB had significantly higher lipid content compared to the untreated biomass. 
Biomass treated with UVB of $6 \mathrm{~kJ} / \mathrm{m}^{2} /$ day and $16 \mathrm{~kJ} / \mathrm{m}^{2} /$ day showed significant decrease in the relative amount of PUFA compared to untreated biomass, however there was no significant difference between the biomass treated by $3 \mathrm{~kJ} / \mathrm{m}^{2} /$ day and $6 \mathrm{~kJ} / \mathrm{m}^{2} / \mathrm{day}$. Content of the highly sensitive eicosapentaenoic acid (EPA) in the $N$. oceanica biomass decreased significantly after exposure to UVB. Content in the untreated biomass was $21.06 \pm 0.07 \%$ of total fatty acids, compared to $16.93 \pm 0.09 \%$ of total fatty acids in the biomass treated by $16 \mathrm{~kJ} / \mathrm{m}^{2} /$ day (data not shown).

Growth of $N$. oceanica under different treatments was monitored over 7 days in experiment 1 (Figure 2). Biomass increment data showed that the increase in duration of UVB exposure resulted in lower biomass accumulation. The highest biomass increment was detected in untreated biomass for the first 4 days. However, after 4 days there was no significant difference in biomass accumulation for untreated and treated biomass, $3 \mathrm{~kJ} / \mathrm{m}^{2} /$ day and $6 \mathrm{~kJ} / \mathrm{m}^{2} / \mathrm{day}$, respectively. Cultures treated for 16 and $22 \mathrm{~kJ} / \mathrm{m}^{2} /$ day showed significantly lower biomass accumulation.

\section{Discussion}

It is already known that the conventional belief of vitamin $\mathrm{D}_{3}$ as an 'animal form of vitamin D' is not valid anymore. Vitamin $\mathrm{D}_{3}$ has been identified within the few plant species of Solanaceae family (Boland, Skliar, Curino \& Milanesi, 2003), and in UVB-exposed leaves from tomato and bell pepper (Jäpelt \& Jakobsen, 2013). This present cultivation study is the first that demonstrates the ability of microalgal species to produce vitamin $\mathrm{D}_{3}$. As mentioned earlier, microalgae represent the primary source of vitamins in aquatic food chains. Since phytoplankton usually habitats the surface of the water, the presence of vitamin $\mathrm{D}_{3}$ most likely originates from UV radiation of provitamin 7-dehydrocholesterol. However, these assumptions were not yet confirmed. Partly because of the challenge it is to quantify vitamin $\mathrm{D}_{3}$ by a specific method and partly because the studies did not include specific strains.

\subsection{Effect of UVB exposure on variation in vitamin $D_{3}$ content in Nannochloropsis oceanica}

The results clearly showed that the vitamin $\mathrm{D}_{3}$ concentration in the biomass of $N$. oceanica increased by the increase of the UVB dose provided. (Table 1, Figure 1). At the highest UVB dose tested at $36 \mathrm{~kJ} / \mathrm{m}^{2} /$ day the content was $1 \pm 0.3 \mu \mathrm{g}$ vitamin $\mathrm{D}_{3} / \mathrm{g}$ dry matter (Figure $1 \mathrm{~b}$ ). There are only a few studies reporting the occurrence of vitamin $\mathrm{D}_{3}$ in microalgae. Sunita Rao and 
260

261

262

263

264

265

266

267

268

269

270

271

272

273

274

275

276

277

278

279

280

281

282

283

284

285

286

287

288

289

290

291

Raghuramulu (1996) examined mixed phytoplankton consisting of the green algae Pediastrum, Scenedesmus, Crucigenia, Coelastrum, Chlorella, and Cosmarium; blue green algae Gomphosphania and Oscillatoria; brown algae Gomphonema, Synedra, Navicula, and Cyclotella. They reported content of vitamin $\mathrm{D}_{3}$ to be $0.8 \mu \mathrm{g} / \mathrm{g}$ dry matter in phytoplankton of fresh water species. Takeuchi et al. (1991) reported $0.15 \mu \mathrm{g} / \mathrm{g}$ of vitamin $\mathrm{D}_{3}$ in dry matter of phytoplankton during the summer in Biwa Lake, Japan. And finally, Brown, Mular, Miller, Farmer \& Trenerry (1991) studied content of vitamins in four micraoalgal species, Tetraselmis, Pavlova, Stichococcus, Nannochloropsis, and reported the content of vitamin $\mathrm{D}_{3}$ below the detection limit in all four cases $(<0.35 \mu \mathrm{g} / \mathrm{g}$ dry matter $)$.

To ensure a higher dietary intake of vitamin $\mathrm{D}_{3}$ in the population voluntary or mandatory fortification of foods in margarine and milk products are used (Pilz et al., 2018). Due to difference in the dietary intake of these food groups among people a more optimal strategy will be to broaden the range of foods with a higher amount of vitamin $\mathrm{D}_{3}$ through fortification and biofortification (Cashman \& Kiely, 2016). Salmon is generally regarded as being high in vitamin $\mathrm{D}_{3}$. Recently, salmon was reported to contain 2.3-7.3 $\mu \mathrm{g} / 100 \mathrm{~g}$ for farmed species and 6.7-26.6 $\mu \mathrm{g} / 100 \mathrm{~g}$ for wild caught (Jakobsen, Smith, Bysted \& Cashman, 2019). Egg is another vitamin $\mathrm{D}_{3}$ rich source with a content at $2.3 \mu \mathrm{g} / 100 \mathrm{~g}$, but as for farmed fish the content in eggs depends on the vitamin $\mathrm{D}_{3}$ content in feed, and for pork and beef the vitamin $\mathrm{D}_{3}$ content also depends on the fat content (Danish Food Composition Database, 2019). The biofortification strategy by feeding may alternatively be performed by UVB exposure. For husbandry e.g. UVB-exposure of pigs in their indoor facilities increased the vitamin $\mathrm{D}_{3}$ content in pork at least 10 times, up to 3 $\mu \mathrm{g}$ vitamin $\mathrm{D}_{3} / 100 \mathrm{~g}$, while UVB exposure of mushrooms can create a content of vitamin $\mathrm{D}_{2}$ up to $80 \mu \mathrm{g} / \mathrm{g}$ dry matter (Urbain, Valverde \& Jakobsen, 2016; Barnkob et al., 2019). In the EU vitamin D enriched mushrooms are approved at a level of $20 \mu \mathrm{g}$ vitamin $\mathrm{D}_{2} / 100 \mathrm{~g}$ (Commission Implementing Regulation (EU) 2018/1011). The EFSA Panel on Nutrition, Novel Foods and Food Allergens (2020) concluded that the UVB exposed mushroom powder (containing 100-130 $\mu \mathrm{g}$ vitamin $\mathrm{D}_{2} / 100 \mathrm{~g}$ ) is safe to use for general population. The similar content of vitamin $\mathrm{D}_{3}$ was found in $N$. oceanica $(100 \pm 30 \mu \mathrm{g} / 100 \mathrm{~g})$. These findings call for a further investigation as this could be a new sustabinable source for vitamin $\mathrm{D}_{3}$. The microalgae $N$. oceanica is not yet approved for human consumption, therefore necessary approval e.g. in Europe as a novel food, may either be as a food or an ingredient. Microalgae might be used in fortified food (e.g. juice or bread) or as supplement, especially for vegetarians and vegans.

\subsection{Origin of vitamin $\mathrm{D}_{3}$ in Nannochloropsis oceanica}


293

Presence of vitamin $\mathrm{D}_{3}$ in $N$. oceanica indicates high levels of provitamin 7-dehydrocholesterol in this species, which is being converted to vitamin $\mathrm{D}_{3}$ by UVB exposure. Sterols in microalgae display large diversity due to the wide phylogenetic heterogeneity and the long evolutionary distance among them. Microalgal sterol composition varies also upon different growth stage, temperature, light intensity and spectra (Véron, Billard, Dauguet \& Hartmann, 1996). Interestingly, $N$. oceanica sterol biosynthetic pathway shares structure and sterol profiles features with both animals and plants (including green algae). The key enzyme catalyzing sterol side chain reduction (sterol-24(25)-reductase) is different from that of higher plants. Amino acid sequence analysis of the enzyme showed that is clustered with that of Choanoflagellates (assumed to be unicellular ancestor of animals) (Lu et al. 2014), which suggests the origin of $N$. oceanica. Cholesterol has been found to be the most abundant sterol in $N$. oceanica, 70-75\% of the total sterol content, while only a minor amount of the phytosterols was found ( $\mathrm{Lu}$ et al. 2014). In plants, cholesterol is normally a minor component among sterols, and it usually constitutes from $1 \%$ to $5 \%$ of the overall sterol composition, while phytosterols are the dominant sterols in plants (Carland, Fujioka \& Nelson, 2010). This unusual feature most likely explains the ability of $N$. oceanica to produce vitamin $\mathrm{D}_{3}$. Existing literature describing the presence and regulation of vitamin $\mathrm{D}_{3}$ and 7-dehydrocholesterol in microalgae and plants has been reviewed (Jäpelt and Jakobsen, 2013), but knowledge is still very limited. However, the presence of cholesterol in some of the microalgal species raises the possibility that 7-dehydrocholesterol could be formed in these organisms. Since the other cultivated species were not able to synthesize vitamin $\mathrm{D}_{3}$ after UVB exposure, it can be suggested that tested strains of Chlorella minutissima, Arthrospira maxima and Rhodomonas salina do not contain 7-dehydrocholesterol.

\subsection{Changes in the microalgal biomass as a result of UVB exposure}

Microalgal growth is considered an important parameter that integrates stress effects in several biochemical processes. Figure 2 shows that there was no significant difference in the biomass accumulation from day 4 between the cultures that received the two lower UVB doses, $3 \mathrm{~kJ} / \mathrm{m}^{2} /$ day or $6 \mathrm{~kJ} / \mathrm{m}^{2} /$ day, compared to the control. Cultures that have received UVB doses of $16 \mathrm{~kJ} / \mathrm{m}^{2} /$ day or $22 \mathrm{~kJ} / \mathrm{m}^{2} /$ day showed significantly lower biomass accumulation compared to the rest of the cultures. It can be observed that the time of adaptation (lag growth phase) was longer for the cultures that received higher UVB doses. However, all the cultures showed ability to grow or survive the given UVB doses since there was no decrease in the biomass accumulation in any of the cultures. There are a few studies on the effect of UVB on growth in microalgae (Suresh, Joshi \& Viswanathan, 1998; Van de Poll, Eggert, Buma \& Breemann, 2001; Kumar, Nanda, 
Kumar \& Chauhan, 2018). The results have mostly showed negative effect of UVB on the growth of algae, which is in the agreement with our results. Suresh et al. (1998) investigated effects of UVB on the growth and composition of cyanobacteria Nostoc spp. UVB dose of only $3 \mathrm{~kJ} / \mathrm{m}^{2} /$ day (for four days) resulted in the reduction of growth by 50\%. Further increase in the UVB dose to $4 \mathrm{~kJ} / \mathrm{m}^{2} /$ day showed total inhibition in the growth of the culture. It was suggested that the total inhibition happened due to irreversible damage to photosynthetic apparatus (Quesada \& Vincent, 1997). Based on the comparison of these studies with the current one, it can be noticed that $N$. oceanica exhibited high damage resistance towards UVB considering the drastically higher UVB doses applied.

Enhanced UVB exposure on microalgae may result in damaging cells and on the other hand may exhibit protection or defense mechanisms to prevent the cell death (Xue, Zhang, Zhang, An \& Wang, 2005). Microalgae face high levels of stress when exposed to UVB exposure and were usually found to respond with reversible photoinhibition (Franklin, Osmond \& Larkum, 2003; García-Gómez, Parages, Jiménez, Palma, Mata \& Segovia, 2012). Therefore, UVB radiation may affect primarily photosynthesis but also growth, pigmentation, general metabolism, and nitrogen fixation (Xue et al. 2005). These effects are the results of either direct impact of UVB on membrane proteins, DNA, enzymes and pigments or indirect impact of UVB by the formation of reactive oxygen species. Kumar, Tyagi, Nath Jha, Srinivas \& Singh (2003) studied protective mechanisms against UVB damage in microalgae and reported the presence of photoreactivation mechanism, which allows survival under natural conditions, even under continuous exposure to UVB. The "safe" dose of UVB will depend upon the species, but if growth is being observed under UVB exposure it suggests the presence of the photoreactivation mechanisms in the cells. In addition, repair-capacity increases when UVB exposure is accompanied by low intensity visible light (below $300 \mu \mathrm{mol}$ photon $/ \mathrm{m}^{2} / \mathrm{s}$ ) because it is assumed that the visible light can enhance protection against photo-damage. Several microalgal species are able to produce UVabsorbing compounds, which may protect cells from unwanted effects of UVB (Pangestuti, Siahaan \& Kim, 2018). Some of the most known compounds are water soluble mycosporine-like amino acids and pigment scytonemin. Further studies are needed to confirm whether such compounds were formed in N. oceanica. Besides UV absorbing compounds, another result of the UVB exposure may be the accumulation of detoxifying enzymes such as superoxide dismutase, catalase and quenching agents like carotenoids. However, in the present study the content of carotenoids decreased with increasing exposure to UVB. Even though carotenoids may be 
synthesized in microalgae due to the UVB exposure, at the high UVB doses, such as above 3 $\mathrm{kJ} / \mathrm{m}^{2} /$ day, they can be rapidly oxidized in order to protect the cells against the photo-damage.

Microalgae are of industrial interest because of their e.g. rapid growth and ability to synthesize large amounts of lipids, high-value PUFAs and carotenoids. These high value compounds were highly affected by the UVB exposure. Lipid content of $N$. oceanica significantly decreased after applying UVB dose of $3 \mathrm{~kJ} / \mathrm{m}^{2} /$ day and $6 \mathrm{~kJ} / \mathrm{m}^{2} /$ day, but interestingly $\mathrm{UVB}$ dose of $16 \mathrm{~kJ} / \mathrm{m}^{2} /$ day resulted in the significant increase in lipid content. It is known that some microalgal species can accumulate lipids as a result of environmental stress, which could be the reason why the lipid content increased after the exposure to such a high dose of UVB. Microalgae have the ability to overproduce lipids under stress condition such as high salt concentrations, high light intensities, or nutrient limitation (Sun, Ren, Zhao, Ji \& Huang, 2018). However, that means that the two other tested UVB doses do not represent the environmental stress for $N$. oceanica, which is also supported by the growth trend data (Figure 2). Furthermore, it can be assumed that the decrease in the lipid content of the cultures exposed to the lower UVB doses was a result of a biosynthetic shift towards production of carbohydrate and protein. However, more experiments need to be carried out to confirm these assumptions.

Our study revealed decrease in PUFAs, carotenoids and chlorophylls content compared to the control. PUFAs content decreased $9 \%$ when exposing cultures to $3 \mathrm{~kJ} / \mathrm{m}^{2} /$ day and $6 \mathrm{~kJ} / \mathrm{m}^{2} /$ day compared to the control. After exposing the culture to $16 \mathrm{~kJ} / \mathrm{m}^{2} /$ day, PUFAs content decreased 18\%. Kumar et al. (2018) examined the effect of UVB light on the content of carotenoids and fatty acids in microalga Chlorella sorokiniana. The given UVB dose was $0.04 \mathrm{~kJ} / \mathrm{m}^{2} / \mathrm{day}$ for four days. They reported a decrease in the lipid content of $19 \%$ compared to control. Similar to the current study, they have observed an increase in monounsaturated fatty acids (MUFAs) and a decrease in PUFAs levels, which is most likely the result of lipid oxidation. Also, another suggestion is that for PUFA synthesis high levels of the adenosine triphosphate (ATP) molecules are required, but under UVB exposure, ATP is being used by the different mechanisms in order to protect the cell against intracellular oxidative stress (Talero, García-Mauriño, Ávila-Román, Rodríguez-Luna, Alcaide \& Motilva, 2015). Carotenoids and chlorophylls showed the same pattern as the PUFAs, with the maximum decrease of $76 \%$ and $81 \%$, respectively. Suresh et al. (1998) reported a chlorophyll content reduction of $26 \%$ and $35 \%$ when the Nostoc spp. cultures were exposed to UVB at $3 \mathrm{~kJ} / \mathrm{m}^{2} /$ day and $4 \mathrm{~kJ} / \mathrm{m}^{2} /$ day, respectively. A significant decrease in carotenoid contents was also observed in UV treated biomass with $31.4 \%$ decrease compared to control. 


\section{Conclusion and perspectives}

392

393

394

395

396

397

398

399

400

401

402

403

404

405

406

407

408

409

410

411

412

413

414

415

416

417

418

Microalga Nannochloropsis oceanica was able to naturally produce high levels of vitamin $\mathrm{D}_{3}$ by exposure to artificial UVB. Chlorella minutissima, Arthrospira maxima and Rhodomonas salina were not able to produce vitamin $\mathrm{D}_{3}$ and the UVB exposure had inhibitory effect on their growth. For $N$. oceanica vitamin $\mathrm{D}_{3}$ production was significantly enhanced by increasing the dose of the UVB exposure and there was a linear relationship between the dose and the vitamin $\mathrm{D}_{3}$ production. High UVB doses were shown to have an adverse effect on the growth and content of PUFAs, chlorophylls and carotenoids. These findings suggest that $N$. oceanica exposed to artificial UVB could be used as a new natural source of vitamin $\mathrm{D}_{3}$.

Microalgae are an extremely diverse group of organisms with a long evolutionary history, and therefore, it is still hard to make any conclusions about microalgae and vitamin $\mathrm{D}_{3}$ production in general. Based on this study, for microalgae $N$. oceanica, UVB dose of $6 \mathrm{~kJ} / \mathrm{m}^{2} /$ day may be suggested as a compromise, where biomass will contain sufficient amounts of vitamin $\mathrm{D}_{3}$, PUFAs and carotenoids.

These findings may present a new opportunity for a biorefinery concept for microalgae in which both PUFAs, vitamin D and pigments could be obtained. Though, more research needs to be conducted in order to determine the presence of vitamin $\mathrm{D}_{3}$ in other microalgal species considering geographic factors including the areas with the high light intensities over the year that might provide the UVB dose that can naturally trigger the production of vitamin $\mathrm{D}_{3}$. Another important task to be considered is evaluating both bioaccessibility and bioavailability of vitamin $\mathrm{D}_{3}$ from $N$. oceanica in order to discuss the potential role of microalgae as a new natural source of vitamin $\mathrm{D}_{3}$ in human diet.

Conflict of interest: The authors' declares that they have no conflict of interest.

Funding: This research did not receive any specific grant from funding agencies in the public, commercial, or not-for-profit sectors.

\section{Literature}

Barnkob, L. L., Petersen, P. M., Nielsen, J. P., \& Jakobsen, J. (2019). Vitamin D enhanced pork from pigs exposed to artificial UVB light in indoor facilities. European Food Research and Technology, 245, 411-418. https://doi.org/10.1007/s00217-018-3173-6. 
Bligh, E.G., \& Dyer, W.J. (1959). A rapid method of total lipid extraction and purification. Canadian Journal of Biochemistry and Physiology, 37, 911-917. https://doi.org/10.1139/o59-099.

424

Boland, R., Skliar ,M., Curino, A., \& Milanesi, L. (2003). Vitamin D compounds in plants. Plant Science, 164, 357-369. https://doi.org/10.1016/S0168-9452(02)00420-X.

Brown, M., Mular, M., Miller, I., Farmer, C., \& Trenerry, C. (1999). The vitamin content of microalgae used in aquaculture. Journal of Applied Phycology, 11, 247-255.

https://doi.org/10.1023/A:1008075903578.

Carland, F., Fujioka, S., \& Nelson, T. (2010). The sterol methyltransferases SMT1, SMT2, and SMT3 influence Arabidopsis development through nonbrassinosteroid products. Plant Physiology, 153, 741 756. https://doi.org/10.1104/pp.109.152587.

Cashman, K. D., Dowling, K.G., Skrabakova, Z., Gonzalez-Gross, M., Valtuena, J., De Henauw, S., Moreno, L., Damsgaard, C.T., Michaelsen, K.F., Molgaard, C., Jorde, R., Grimnes, G., Moschonis, G., Mavrogianni, C., Manios, Y., Thamm, M., Mensink, G. B., Rabenberg, M., Busch, M. A., Cox, L., Meadows, S., Goldberg, G., Prentice, A., Dekker, J. M., Nijpels, G., Pilz, S., Swart, K. M., van Schoor, N. M., Lips, P., Eiriksdottir, G., Gudnason, V., Cotch, M. F., Koskinen, S., Lamberg-Allardt, C., Durazo-Arvizu, R. A., Sempos, C. T. \& Kiely, M. (2016a) Vitamin D deficiency in Europe-Pandemic? The American Journal of Clinical Nutrition, 103, 1033-1044. https://doi.org/10.3945/ajcn.115.120873.

Cashman, K. D., \& Kiely, M. (2016b). Tackling inadequate vitamin D intakes within the population: fortification of dairy products with vitamin D may not be enough. Endocrine 51, 38-46. https://doi.org/10.1007/s12020-015-0711-x.

Danish Food Composition Databank, version 4. (2019). Department of Nutrition, National Food Institute, Technical University of Denmark. http://www.foodcomp.dk/Accessed 8 September 2019.

EFSA NDA Panel (EFSA Panel on Dietetic Products, Nutrition and Allergies). (2016). Scientific opinion on dietary reference values for vitamin D. EFSA Journal, 14, 4547. https://doi.org/10.2903/j.efsa.2016.4547.

EFSA NDA Panel (EFSA Panel on Nutrition, Novel Foods and Food Allergens). (2020). Scientific opinion on the safety of vitamin $\mathrm{D}_{2}$ mushroom powder as a novel food pursuant to Regulation (EU) 2015/2283. EFSA Journal, 18(1), 5948-5971. https://doi.org/10.2903/j.efsa.2020.5948.

Firestone, D.A.O.A.C. (2009). Official Methods and Recommended Practices of the AOCS, 5th ed.; American Oil Chemist's Society. Urbana, IL, USA. 
453 photosynthesis. In Larkum, A. W. D., Douglas, S. E. \& Raven, J. A. (Eds.), Photosynthesis in algae (pp. 454 277-304). Advances in Photosynthesis and Respiration, vol 14. Springer, Dordrecht.

455 García-Gómez, C., Parages, M. L., Jiménez, C., Palma, A., Mata, M. T., \& Segovia, M. (2012). Cell 456 survival after UV radiation stress in the unicellular chlorophyte Dunaliella tertiolecta is mediated by 457 DNA repair and MAPK phosphorylation. Journal of Experimental Botany, 63(14), 5259-5274. 458 https://doi.org/10.1093/jxb/ers185.

459 Guillard, R. R. L., \& Ryther, J. H. (1962). Studies on marine planktonic diatoms I. Cyclotella nana 460 Hustedt and Detonula confervacea (Cleve) Gran. Canadian Journal of Microbiology, 8, 229-239. 461 https://doi.org/10.1139/m62-029.

462 Hilger, J., Friedel, A., Herr, R., Rausch, T., Roos, F., Wahl, D.A., Pierroz, D.D., Weber, P., \& 463 Hoffmann, K. (2014). A systematic review of vitamin D status in populations worldwide. British 464 Journal of Nutrition, 111, 23-45. https://doi.org/10.1017/S0007114513001840.

465 Holick, M.F. (2017). The vitamin D deficiency pandemic: approaches for diagnosis, treatment and 466 prevention. Reviews in Endocrine and Metabolic Disorders, 18:153-65. https://doi.org/10.1007/s11154467 017-9424-1.

468 International Standard Organization, ISO/IEC 17025. (2017). General requirements for the competence 469 of testing and calibration laboratories. International Standards, 1-29.

470 IOM, Institute of Medicine. (2011). Committee to review dietary reference intakes for vitamin D and 471 calcium. In Ross, A. C., Taylor, C. L., Yaktine, A.L. \& Del Valle, H. B. (Eds.), Dietary reference 472 intakes for calcium and vitamin D. National Academies Press, Washington, USA.

473 Jakobsen, J., \& Smith, C. (2017). Farmed salmon and farmed rainbow trout - excellent sources of 474 vitamin D? Fisheries and Aquaculture Journal, 8(2), 1-5. http://doi.org/10.4172/2150-3508.1000204.

475 Jäpelt, R. B., \& Jakobsen, J. (2013). Vitamin D in plants: a review of occurrence, analysis, and 476 biosynthesis. Frontiers in Plant Science, 4, 136. https://doi.org/10.3389/fpls.2013.00136.

477 Kumar, A., Tyagi, M. B., Nath Jha, P., Srinivas, G., Singh, A. (2003). Inactivation of cyanobacterial 478 nitrogenase after exposure to ultraviolet-B radiation. Current Microbiology, 46, 380-384,

479 Kumar, V., Nanda, M., Kumar, S., \& Chauhan, P. K. (2018). The effects of ultraviolet radiation on 480 growth, biomass, lipid accumulation and biodiesel properties of microalgae. Energy Sources Part A 481 Recovery Utilization and Environmental Effects, 40(7), 787-793,

482 https://doi.org/10.1080/15567036.2018.1463310. 

cholesterol biosynthetic pathway and its integration with fatty acid biosynthesis in the oleaginous microalga Nannochloropsis oceanica. Biotechnology for Biofuels 7, 81.

NNR, Nordic Nutrient Recommendation. (2014). Nordic Council of Ministers. 5(11), 1. http://dx.doi.org/10.6027/Nord2014-002/Accessed 13 September 2019.

O’Neill, C. M., Kazantzidis, A., Ryan, M. J., Barber, N., Sempos, C. T., Durazo-Arvizu, R. A., Jorde, R., Grimnes, G., Eiriksdottir, G., Gudnason, V., Cotch, M. F., Kiely, M., Webb, A. R., \& Cashman, K. D. (2016). Seasonal changes in vitamin D-effective UVB availability in Europe and associations with population serum 25-hydroxyvitamin D. Nutrients, 8(9), 533. https://doi.org/10.3390/nu8090533

Pangestuti, R., Siahaan, E. A., \& Kim, S. K. (2018). Photoprotective substances derived from marine algae. Marine Drugs, 16(11), 399. https://doi.org/10.3390/md16110399.

Pilz, S., März, W., Cashman, K. D., Kiely, M. E., Whiting, S. J., Holick, M. F., Grant, W. B., Pludowski, P., Hiligsmann, M., Trummer, C., Schwetz, V., Lerchbaum, E., Pandis, M., Tomaschitz, A., Grübler, M. R., Gaksch, M., Verheyen, N., Hollis, B. 'W., Rejnmark, L., Karras, S. N., Hahn, A., Bischoff-Ferrari, H. A., \& Reichrath, J. (2018). Rationale and plan for vitamin D food fortification: A review and guidance paper. Frontiers in Endocronology, 9, 373. https://doi.org/10.3389/fendo.2018.00373.

Safafar, H., van Wagenen, J., Møller, P., \& Jacobsen, C. (2015). Carotenoids, phenolic compounds and tocopherols contribute to the antioxidative properties of some microalgae species grown on industrial wastewater. Marine Drugs, 13, 7339-7356. https://doi.org/10.3390/md13127069.

Sun, X., Ren, L., Zhao, Q., Ji, X., \& Huang, H. (2018). Microalgae for the production of lipid and carotenoids: a review with focus on stress regulation and adaptation. Biotechnology for Biofuels, 11, 272. https://doi.org/10.1186/s13068-018-1275-9.

Sunita Rao, D., \& Raghuramulu, N. (1996). Food chain as origin of vitamin D in fish. Comparative Biochemistry \& Physiology, 114, 15-19. https://doi.org/10.1016/0300-9629(95)02024-1.

Suresh, B. G., Joshi, P. C., \& Viswanathan, P. N. (1998). UVB-Induced reduction in biomass and overall productivity of cyanobacteria. Biochemical and Biophysical Research Communications 244, 138-142. https://doi.org/10.1006/bbrc.1998.8224.

Takeuchi, A., Okano, T., Tanda, M., \& Kobayashi, T. (1991). Possible origin of extremely high contents of vitamin $\mathrm{D}_{3}$ in some kinds of fish liver. Comparative Biochemistry \& Physiology A, 100, 483-487. https://doi.org/10.1016/0300-9629(91)90504-6. 
513 Talero, E., García-Mauriño, S., Ávila-Román, J., Rodríguez-Luna, A., Alcaide, A., \& Motilva, V.

514 (2015). Bioactive compounds isolated from microalgae in chronic inflammation and cancer. Marine

515 Drugs, 13(10), 6152-6209. https://doi.org/10.3390/md13106152.

516 Urbain, P., Valverde, J. \& Jakobsen, J. (2016). Impact on vitamin $\mathrm{D}_{2}$, itamin $\mathrm{D}_{4}$ and agaritine in

517 Agaricus bisporus mushrooms after artificial and natural solar UV light exposure. Plant Foods for

518 Human Nutrition, 71, 314-321. https://doi.org/10.1007/s11130-016-0562-5

519 Van de Poll, W. H., Eggert, A., Buma, A., \& Breemann, A. (2001). Effects of UVB-induced DNA

520 damage and photoinhibition on growth of temperate marine red macrophytes: Habitat-related

521 differences in UV-B tolerance. Journal of Phycology, 37, 30-37. https://doi.org/10.1046/j.1529-

$522 \quad 8817.2001 .037001030 . x$.

523 Véron, B., Billard, C., Dauguet, J.C., \& Hartmann, M.A. (1996). Sterol composition of Phaeodactylum

524 tricornutum as influenced by growth temperature and light spectral quality. Lipids, 31, 989-994.

525 https://doi.org/10.1007/BF02522694.

526 Walne, P. R. (1970). Studies on the food value of nineteen genera of algae to juvenile bivalves of the

527 genera Ostrea, Crassostrea, Mercenaria, and Mytilis. Fish. Invest. 26, 1-62.

528 Webb, A.R. (2006). Who, what, where and when - influences on cutaneous vitamin D synthesis.

529 Progress in Biophysics and Molecular Biology, 92(1), 17-25.

530 https://doi.org/10.1016/j.pbiomolbio.2006.02.004.

531 Xue, L., Zhang, Y., Zhang, T., An, L., \& Wang, X. (2005). Effects of enhanced ultraviolet-B radiation 532 on algae and cyanobacteria. Critical Reviews in Microbiology, 31(2), 79-89.

533 https://doi.org/10.1080/10408410590921727

534 Zarrouk, C. (1966). Contribution a l'étude du cyanophycée. Influence de divers facteurs physiques et 535 chimiques sur la croissance et la photosynthèse de Spirulina maxima (Setch et Gardner) Geitl., PhD, 536 Paris, France. 
544 Figure 1. Changes in content of vitamin $\mathrm{D}_{3}(\mu \mathrm{g} / \mathrm{g}$ dry matter) in microalgae Nannochloropsis 545 oceanica treated with UVB (a) dose of $15 \mathrm{~kJ} / \mathrm{m}^{2} /$ day over different number of days (b) at different 546 distances between the culture and the UVB source: $5 \mathrm{~cm}\left(36 \mathrm{~kJ} / \mathrm{m}^{2} /\right.$ day $), 10 \mathrm{~cm}\left(22 \mathrm{~kJ} / \mathrm{m}^{2} /\right.$ day $)$ 547 and $15 \mathrm{~cm}\left(15 \mathrm{~kJ} / \mathrm{m}^{2} /\right.$ day $)$, after 5 days. The standard deviations are presented as bars $(\mathrm{n}=3)$. 548 Different letters above the bars represent significant differences $(p<0.05)$.

549 Figure 2. Effect of different dose of UVB on growth of Nannochloropsis oceanica. The standard 550 deviations are presented as bars $(n=3)$.

LIST OF TABLES:

553 Table 1. Content of vitamin $\mathrm{D}_{3}(\mu \mathrm{g} / \mathrm{g}$ dry matter) in tested microalgal species treated with 554 different doses of UVB $\left(\mathrm{kJ} / \mathrm{m}^{2} /\right.$ day) for 7 days. Values are expressed as mean $\pm \mathrm{SD}$ of $\mathrm{n}=3$. 555 Different letters in the same row represent significant differences $(\mathrm{p}<0.05)$.

556 Table 2. Concentration of the lipid, PUFA, carotenoid and chlorophyll of the microalga 557 Nannochloropsis oceanica treated with different doses of UVB for 7 days. Values are expressed 558 as mean \pm SD of $n=3$. Different letters in the same column represent significant differences ( $p$ $559<0.05)$. 
Vitamin $D_{3}$ ( $\mu \mathrm{g} / \mathrm{g}$ dry matter)

\begin{tabular}{ccccc}
\hline $\begin{array}{c}\text { UVB dose } \\
\left(\mathbf{k J} / \mathbf{m}^{2} / \mathbf{d a y}\right)\end{array}$ & $\begin{array}{c}\text { Nannochloropsis } \\
\text { oceanica }\end{array}$ & $\begin{array}{c}\text { Rhodomonas } \\
\text { salina }\end{array}$ & $\begin{array}{c}\text { Arthrospira } \\
\text { maxima }\end{array}$ & $\begin{array}{c}\text { Chlorella } \\
\text { minutissima }\end{array}$ \\
\hline 0 & $<0.004$ & $<0.004$ & $<0.004$ & $<0.004$ \\
3 & $0.09 \pm 0.01^{\mathrm{c}}$ & $<0.004$ & $<0.004$ & $<0.004$ \\
6 & $0.29 \pm 0.00^{\mathrm{b}}$ & $<0.004$ & $<0.004$ & $<0.004$ \\
16 & $0.42 \pm 0.04^{\mathrm{a}}$ & $<0.004$ & $<0.004$ & $<0.004$ \\
22 & $0.48 \pm 0.05^{\mathrm{a}}$ & $<0.004$ & $<0.004$ & $<0.004$ \\
\hline
\end{tabular}

572

573

574 Table 2.

\begin{tabular}{ccccc}
\hline $\begin{array}{c}\text { UVB dose } \\
\left(\mathbf{k J} / \mathbf{m}^{2} / \mathbf{d a y}\right)\end{array}$ & $\begin{array}{c}\text { Total lipids } \\
(\boldsymbol{\%})\end{array}$ & $\begin{array}{c}\text { PUFA } \\
(\boldsymbol{\%} \text { of total FA })\end{array}$ & $\begin{array}{c}\text { Carotenoids } \\
(\mathbf{m g} / \mathbf{g})\end{array}$ & $\begin{array}{c}\text { Chlorophylls } \\
(\mathbf{m g} / \mathbf{g})\end{array}$ \\
\hline $\mathbf{0}$ & $31.4 \pm 1.4^{\mathrm{b}}$ & $27.1 \pm 0.2^{\mathrm{a}}$ & $10.2 \pm 0.9^{\mathrm{a}}$ & $13.7 \pm 0.4^{\mathrm{a}}$ \\
$\mathbf{3}$ & $23.9 \pm 1.3^{\mathrm{c}}$ & $24.6 \pm 0.4^{\mathrm{b}}$ & $6.7 \pm 0.2^{\mathrm{b}}$ & $8.8 \pm 0.4^{\mathrm{b}}$ \\
$\mathbf{6}$ & $25.0 \pm 0.6^{\mathrm{c}}$ & $24.2 \pm 0.1^{\mathrm{b}}$ & $3.3 \pm 0.2^{\mathrm{c}}$ & $4.7 \pm 0.1^{\mathrm{c}}$ \\
$\mathbf{1 6}$ & $36.9 \pm 1.8^{\mathrm{a}}$ & $22.1 \pm 0.4^{\mathrm{c}}$ & $2.4 \pm 0.1^{\mathrm{d}}$ & $3.4 \pm 0.2^{\mathrm{d}}$ \\
\hline
\end{tabular}

575

576

577

578

579

580

581

582

583

584

585 


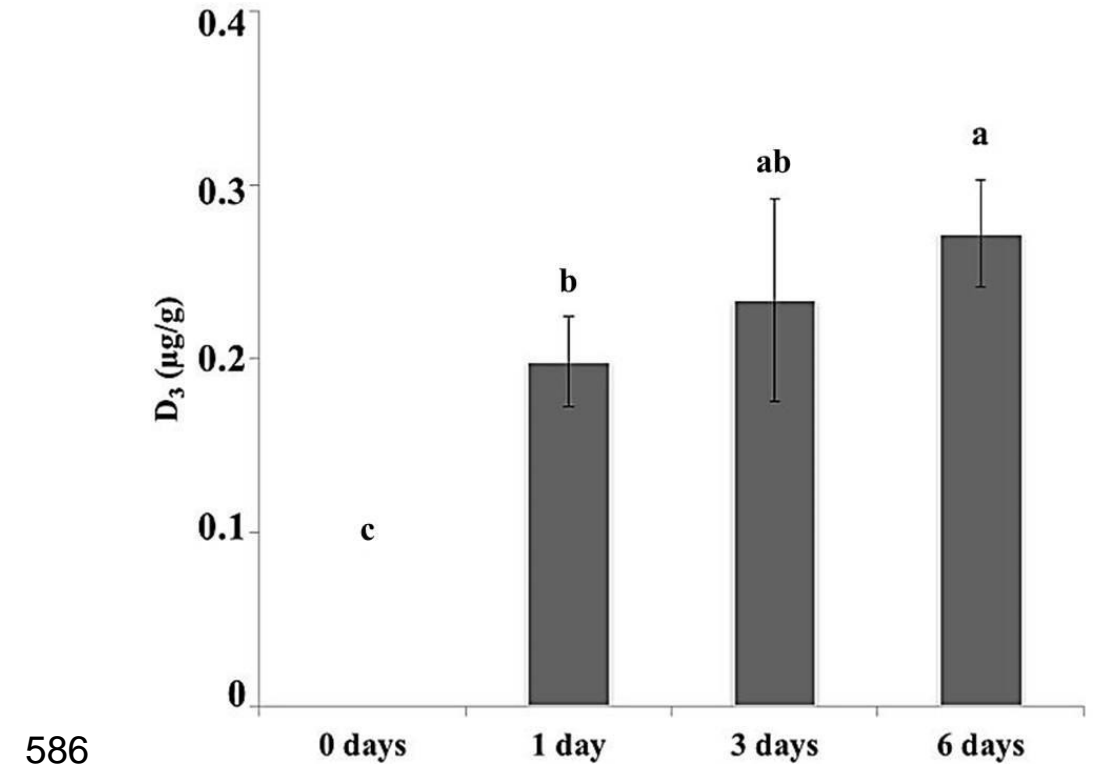

587 Figure 1a.

588

589

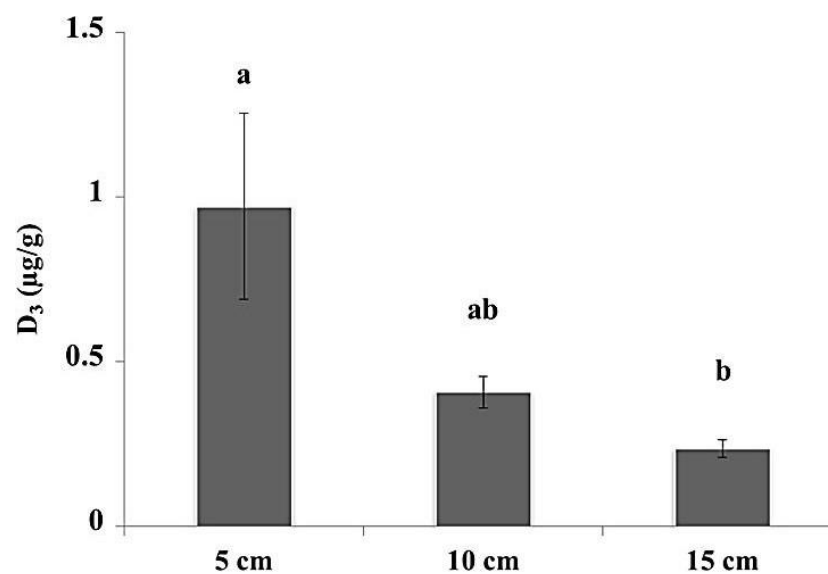

590 Figure 1b.

591 


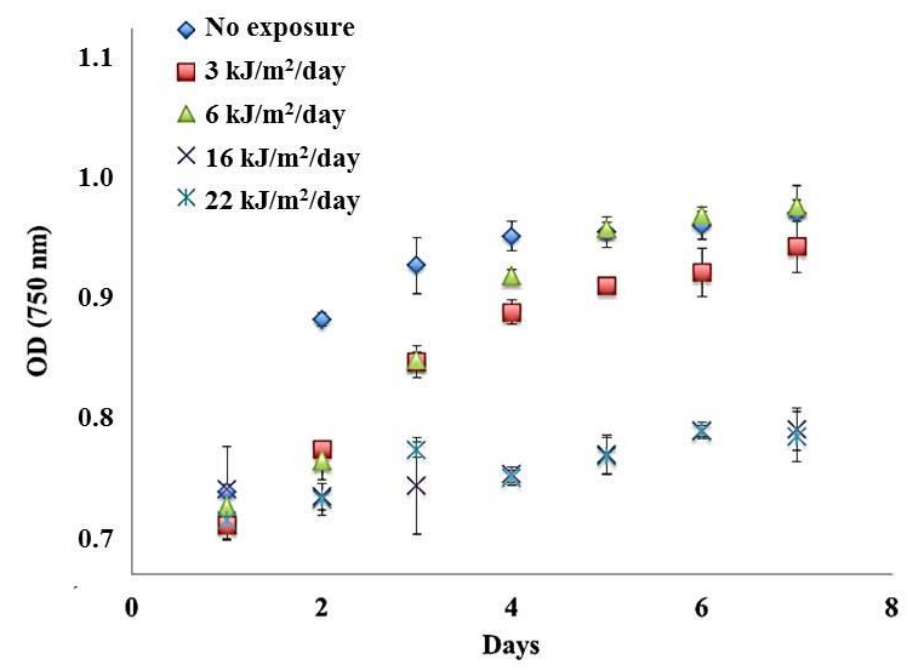

592

593 Figure 2.

594

595 